Pricing the options inherent in leased commercial property: a UK case study

\author{
Andrew Baum \\ Department of Real Estate \& Planning \\ University of Reading Business School \\ UK
}

a.e.baum@reading.ac.uk

With acknowledgements and thanks to Neil Crosby and Patrick McAllister 


\title{
Pricing the options inherent in leased commercial property: a UK case study
}

\author{
Andrew Baum \\ Department of Real Estate \& Planning \\ University of Reading Business School \\ UK
}

\section{Introduction}

This paper sets out the findings of a group of research and development projects carried out at the Department of Real Estate and Planning at the University of Reading and at OPS (Oxford Property Systems, a software development company) over the period 1999-2003.

The projects have several aims. These are: to identify the fundamental drivers of the pricing of different lease terms in the UK property sector; to identify the main variations in UK lease terms; to identify key issues in pricing leases with different lease lengths and other terms; and to develop a model for the pricing of rent under a variety of lease variations.

Although it is possible to model quantitatively both landlords' and tenants' positions, the complexity of the legal and institutional issues that influence the rental impact of lease terms makes a solution to pricing challenging. The approach of valuers and funding criteria also add complexity to the issue and add an institutional dimension to the problem, impeding the adjustment towards rational pricing. The intricacy of these issues possibly explains the conservatism of many market participants towards flexi-leases. However, it also provides a potential opportunity to market participants with the ability to accurately price flexibility in lease terms.

The research uses data derived from major databases maintained by IPD and the Valuation Office, interviews and workshops with over 50 market participants (owners, letting and investment agents, valuers and rent review surveyors). The OPS software development work was based on the outputs of this research.

A key conclusion of this study is that the relative stability of lease terms in the retail and office sectors reflects a widespread mutuality of interests between landlord and tenant in the status quo. Long leases provide important benefits for most retailers in terms of security of trading position and adequate write-off periods, and the fit-out costs for an office user can also encourage longer leases than might otherwise be optimal.

From the landlord's perspective, the main factors driving the required 'compensation' for a lease term amendment include expected rental volatility, expected probability of tenant vacation, and the expected costs of tenant vacation. These data are used in conjunction with simulation technology to reflect the options inherent in certain lease types to explore the required rent adjustment. The resulting cash flows have interesting qualities which illustrate the potential importance of option pricing in a non-complex and practical way.

Finally, there are interesting valuation and pricing issues posed by the introduction of a new variable, rental growth volatility, into an appraisal system. 


\section{Recent developments in leasing practice}

\subsection{Market pressures}

This section, based on work undertaken at the University of Reading in 1998-2001, assesses the changing state of leasing practices in the UK and the institutional factors which have an influence. These factors include the effect of the globalisation of business, the effect of changing working practices, accounting regulations, investment and lending criteria, and the market's ability to price lease contracts. Full details of this research are to be found in Crosby, Murdoch and Markwell (2000) and Baum, Crosby and McAllister (2001).

There is evidence that the internationalisation of business and the increasing flows of foreign investment have changed the pattern of leasing around the world with some resulting convergence in lease lengths, typically meaning shorter leases in the UK.

The evidence of changing business practices and attitudes to space is that businesses require more flexibility, not only in terms of the physical characteristics of buildings but also in terms of leasing arrangements. The identification of core and peripheral activity has already helped to fuel the increasing provision of serviced offices. Changes in locational requirements between city centre and out of town locations in the business space and retailing sectors have also affected the relationship between landlord and tenant.

There is also evidence that the preferences of lenders and investors have affected the landlord and tenant relationship in the form of resistance to new lease forms. Lending criteria concerning interest cover over the loan term and investors' demand for risk reduction have maintained pressure to retain the majority of standard institutional lease terms.

This has been reinforced by the approach of valuers whose valuations underpin financial accounting and performance measurement processes. The lack of sophisticated techniques to price diverse lease terms and the reliance on comparative valuation methods increases the risk to landlords of accepting non standard lease terms.

\subsection{Changing lease structures}

In the Reading research, three datasets were used to measure changes in lease terms over the 1990s. The three sources were IPD; Valuation Office; and auction data. The results are presented in the following sub-sections.

\section{Lease lengths}

Lease lengths were found to have fallen significantly since 1990 . This fall took place mainly in the period 1990 to around 1995. Between 1996 and 2000 average lease lengths remained fairly constant; significantly, there is no evidence that they have risen despite letting markets strengthening considerably in that period. Since 2001 a rapidly weakening occupational market in certain sectors, a specific example being the City office market in 2002, has led to large increases in rent free periods and peripheral terms (liability for uninsurable damage) but not to significant changes in lease lengths, breaks or rent review flexibility.

There is no doubt that the prime retail market commands longer leases than the prime office and industrial markets. The office market reacted first to the recession and average lease lengths fell more sharply and have remained at lower levels. There is evidence that retail tenants, on the other hand, do not want shorter leases. 
Within the retail sector, there appears to be a significant difference between the lease length of retail warehouses and out of town retail parks and the standard high street shop. While the rest of the retail sector responded to the general fall in lease length in the early 1990s, the retail warehouse sector was virtually alone in maintaining its ability to command long leases of 20 and 25 years.

Location quality and the size and value of lettings are significant factors in lease length. Higher quality properties have the highest lease lengths across all sectors. Value-weighted and floorspace-weighted average lease lengths exceed unweighted averages, often by substantial amounts. Major companies occupy on longer terms.

Within the office sector, prime out of town space appears to command similar lease lengths to in town and the main difference is the age, quality, size and value of letting. In the industrial sector, the main factors of size, value, age and quality also determine the lease length.

The average lease length on renewal is lower than that on new letting. This may be due to renewals being of older, more obsolete properties in the office and industrial markets. However, the difference is also very apparent in the retail market, although to a lesser extent.

Across the market as a whole, the most dominant lease term is the very short lease of less than 5 years. By 1998, approximately $50 \%$ of leases were for short terms of less than 5 years. This rises to about $75 \%$ of leases of less than 10 years. This has not happened to the same extent in the institutional market but, by number of leases, leases of less than 10 years still constitute over $50 \%$. Weighted by value, this falls to between $15 \%$ and $25 \%$ depending upon sector. At the high value end the 15 year lease is now standard, with longer leases typical for retail warehouses.

\section{Break clauses}

The use of break clauses accelerated during the early 1990s. Break clauses in leases now usually coincide with review dates, occurring most commonly at five and ten year review points.

\section{Rent review clauses}

There appear to have been no major changes in the nature or process by which rents are reviewed within leases over the 1990s. Forms of review other than to open market rental value are still used very sparingly in the UK property market. There is some evidence that the universality of the upwards only review has weakened but there is also evidence that pressure for change has been resisted strongly by landlords.

The five year interval between reviews remained the norm, and the frequency of use of other periods, such as three years, has remained very low in the retail sector, although $20 \%$ to $25 \%$ of industrial and office leases have three-yearly reviews. Average rent review periods have held up during the study period across all three sectors.

The two changes which have had most effect on rent reviews is the shortening of leases and the increased use of tenants' break provisions which are linked to review dates. The incidence of leases which do not contain reviews has increased significantly across all three sectors since 1990 . In 1990, the number of leases with no reviews was about $25 \%$ in all three sectors. By 1998, it had risen to $80 \%$ in the industrial sector and $70 \%$ in the office sector, although only $35 \%$ of retail leases did not have reviews. 
Repairing liability and service charges

Surveys suggest that there is a fairly even split between full repairing and other repairing liabilities, with higher landlord liabilities in the secondary and tertiary markets. There has been little or no change in this over the 1990s.

\section{Inducements}

The use of inducements such as capital payments to tenants and rent free periods appears to have been a phenomenon of the recessionary market in the early 1990s and very recently. Rent free periods were reported to be the most used incentive in the period 1990 to 1993 and the incidence of their use increased from virtually nothing in 1990 to around $50 \%$ in the office and retail sectors in 1997. Significant rent-free periods re-appeared in certain sectors in the second half of 2002.

\section{Contracting out}

There is very little data available to describe the incidence of contracting out of the Landlord and Tenant Act 1954 right to renew leases. Surveys suggest that the level of contracting out is only 'occasional' and that this has remained fairly constant over the analysis period. However, since the granting of a short lease in a weak letting market lead directly to a new short lease being granted at renewal, landlords increasingly seek to contract out. Survey results suggest that contracting out increased over the 1990s, with a higher incidence in secondary and tertiary rather than prime markets. 


\section{Factors affecting the value effects of lease variations}

The information in this section is derived from the Reading research, 1998-2001, and the OPS work, 2001-2003. This information has been used in the technical development of the OPRent system, or included in its future development programme.

\subsection{Open market lettings}

\section{The landlord perspective}

Flexible leasing creates uncertainty in the cash flow. The long lease with upward only rent reviews on full repairing and insuring terms has the essential advantage of minimising cash flow uncertainty. Modelling the impact of flexible leases introduces the need to deal with uncertain cash flows.

Where break clauses are relevant, the key variable is the probability of the tenant exercising the break and vacating. Where short leases are relevant, the key variable is the probability of lease renewal. In each case, void lengths, empty property costs and re-letting costs are relevant.

Data is limited: there is little empirical evidence of the probability of breaks and lease renewals and void periods. However, even if available, the value of mean figures will be limited since individual features of properties and tenants will affect the propensity of the tenant to vacate, as will the economic environment.

It is apparent that the probability of tenant vacation will be influenced by the nature of the specific tenant, lease, market sector and building as well as market factors. The expected costs and probability of tenant vacation can be specified as a function of many factors.

These include:

- the length of the notice period

- the amount of the financial penalty

- the expected cost of dilapidations

- the estimated amount spent fitting out premises

- the availability of alternative premises

- the estimated costs of relocation

- growth/contraction in the tenant's business

- expected rental growth

The estimated probability of letting termination is the first key variable used in calculating the expected cost of tenant vacation. The second key variable is the expected length of the void period. The expected costs of a void will be a function of the estimated probability of costs being incurred and the amount of these costs. In addition, there is a possibility of a downward rent review.

The probability of the rent passing exceeding rental value at rent review is dependent upon the expected level of rental growth, the time to rent review and the volatility of rental growth.

Hence, in the absence of reliable transaction evidence involving comparable leases, investors' pricing adjustments should be based upon

- expected rental volatility

- expected probability of tenant vacation 
- expected costs of tenant vacation

- expected rental growth

- time to rent review

The tenant perspective

Interviews with practitioners suggest that the economic value put on short leases was variable between tenants. The general impression given was that a majority of retail tenants placed a higher value on securing a trading position than on obtaining flexibility. This is less true of office and industrial tenants.

Tenants who perceive a high degree of risk in a venture or a location will tend to place a high value on a short lease for two main reasons. Firstly, they perceive a need for a certain exit strategy. Secondly, long leases can decrease the project IRR from the tenant's point of view.

However, fit-out costs can be an important variable. Tenants with substantial fit-out costs place little value on short leases since they may need 10-15 year write-off periods to maximise IRR. It was estimated by interviewees that average required write-off periods were 7-8 years.

\section{Expected rent impacts}

The point was strongly made that retailers will not pay a premium rent for flexible leases. The retailer's business plan is very short term. At the same time, landlords will protect investment value: for many of them, successful investment is perceived to be about protecting long income streams, high headline rents and low capitalisation rates. It is not surprising, therefore, that leases shorter than 10 years are rare for prime space in this sector. The main exception to this is the use of rent free periods and capital incentives, each of which will have a direct effect on rent.

In the retail market, rent is typically the first thing agreed. After that, it is a matter of give and take on lease terms. Several interviewees suggested that it will be useful to use a pricing model to examine the rent implications of lease variations in comparable deals done.

Generally, it can be difficult to obtain strong views concerning the rent impact of lease variations as there can be a strong desire to protect the headline rent and to use other lease terms (rent frees, inducements) to compensate for variations. The source of this attitude, which exists at the expense of NPV or IRR maximisation, is a matter of interest connected with valuation practice. Nonetheless, interviews picked up a large amount of opinion and transaction-based evidence of likely rent variations for typical lease alternatives.

Table 1 reports the average expected rent impacts of lease variations across all eight market sectors. This based on workshops held at the offices of the OPRent sponsors, assuming a standard lease of 15 years without breaks on upward only rent reviews every five years with 3-6 months rent free. The impact varies from sector to sector and is depended upon building and location quality. Nonetheless, some patterns emerge. Short leases, for example, are widely regarded as more damaging than short term break clauses. 
Table 1: expected mean rent impacts

\begin{tabular}{|cc|}
\hline Lease variation & Mean rent impact \\
Review 1 break & $10.45 \%$ \\
Review 2 break & $6.60 \%$ \\
All review break & $17.00 \%$ \\
5 year lease & $15.23 \%$ \\
10 year lease & $7.00 \%$ \\
10 year lease, 5 year break & $16.40 \%$ \\
3 year reviews & $-3.79 \%$ \\
Two way reviews & $6.25 \%$ \\
RPI lease & $5.80 \%$ \\
\hline
\end{tabular}

\subsection{Lease length and rent review/lease renewal}

Lease length is an issue in setting rents at rent review. Where the hypothetical lease in the rent review clause has a lease term that is 20-25 years, this tends to be regarded as onerous. As a result, established through precedent and negotiation, discounts of $2.5 \% / 3 \%$ are common for hypothetical unexpired terms in excess of 15 years. However, it is clear that where the unexpired term in the hypothetical leases is 'short' - say five years - landlords are unable to achieve an uplift in rent.

Although the logic of such an uplift is accepted, landlords arguing this point are generally unable to identify evidence of premium rents. Consequently, practitioners were unaware of any precedents establishing an uplift. It is instructive that the only occasion that a break clause is rent sensitive at rent review is when the landlord has an option to determine the lease. In this case, there is evidence of rent discounts at rent review.

In the high street, long leases may lead to rent discounts: 10 years is the minimum needed to maintain ERV, but a hypothetical term of 25 years will produce a discount at review.

Although there is no absolute certainty that tenants will get what they want, the courts will generally be strongly influenced by the existing lease length in setting new leases. They will also take into account market norms and the preferences of the tenant. However, a key point is that tenants who obtain a short lease at lease renewal do not pay a rent premium. There are no precedents of landlords being awarded inflated rents to reflect a break clause/short lease. Conversely, as with rent reviews, there is lots of precedent to suggest that where the landlord has the advantage of a break clause, this can lead to substantial discounts in rent (15\%-20\%).

\subsection{Valuation}

"Valuers have a great and excessive impact" (interviewee).

The importance of valuers and valuation methodology is illustrated by the fact that the required rent effect of a lease variation is often calculated by reference to the yield (valuation) impact of that variation. Say a property let on standard terms is valued by reference to a rental value of $£ 10$ and a yield of $10 \%$. The valuer may be asked to estimate the yield impact of a change from a 15 year lease to a 5 year lease. Assume that the yield moves out to $12 \%$. This leads to a fall in value of $15 \%$. It can be put right by a $15 \%$ rent increase, and this is where many will end their analysis. 
This is not true value maximisation: it is based on likely selling prices, not on cash flows, and is therefore a mechanism based on very short term analysis.

Due to similar considerations, it can be difficult to obtain strong views concerning the rent impact of lease variations, as there can be a strong desire to protect the headline rent and to use other lease terms (rent frees, inducements) to compensate for variations. The source of this attitude is again the protection of the short term valuation rather than the optimisation of the longer term cash flow. Nonetheless, the valuation process is not wholly ignorant of future cash flows.

Discussions with valuers suggest that for properties with short leases, break clauses and imminent lease expiries, the main valuation adjustment is the incorporation of a void allowance in the valuation. Generally this is the case for leases of less than five years unexpired. However, it was pointed out that the void allowance did not reflect the 'true' expected costs of a void. Rather it was moderated to reflect the fact that the tenant would probably not break. Where it was certain that the tenant would break, then a full void allowance was included in the valuation.

An alternative view is that valuers are seen as very influential and cautious. For example, a $100 \%$ chance of break exercise may be assumed by the valuer, while a $50 \%$ chance is assumed by investors.

With regard to break clauses it was stated that notice period and penalty would be factored into the valuation so that a long notice period and substantial rent penalty could neutralise the void allowance. For shopping centres with short leases a valuer would build in a running void assumption into the cash flow based on expected average void rate and expected average void period.

Flexible leasing may lead to faster lettings and less rent free periods. The rental increase available may easily compensate for the risks of voids and re-letting costs. Valuation methodology does not naturally assist in examining this problem, which is regarded as an investment appraisal challenge left for owners and consultants rather than valuers.

Interviewees noted this tension between valuation and investment appraisal approaches. This can lead to different advice being given to lessors by two different departments of the same property consultant - and this is not surprising, because one approach is based on short term sale price protection while the other is based on long term cash flow protection.

\section{Funding}

Funding criteria are often critical to the pricing strategies of private investors. Given that the banks place great importance on unexpired lease terms in their risk management procedures, short leases are undesirable from the landlord's perspective.

The observed capitalisation rate damage that can be observed for leases with less than 10 years unexpired - or 15 in some sectors - can be seen as a rational outcome of financing criteria.

\section{Liquidity}

One consequence of the valuation process may be that short leases tend to be less liquid. Practitioners commented that it was rare to see a property on the market that had less than five years unexpired. Landlords tended to follow one of two strategies. Firstly, they could 
simply wait until the lease had expired and a new lease negotiated before disposal. Alternatively, they could restructure the lease.

Few landlords appear to be prepared to take on what would be a normal challenge in many other markets, namely to provide a level of customer service and the resulting continuation of a customer relationship. This may be the result of the market's excessive reliance on the valuation process accompanied by a lack of faith in its use where there is abnormality and little or no comparable evidence.

\section{The portfolio effect}

Landlords will be more flexible on multi-let schemes than on stand alone leases, partly because of the influence of valuers who will penalise the capitalisation rate for a short lease on a single investment but take the 'tone' of lease lengths for the yield on a multi-let estate.

In addition, lenders may be more relaxed about lending against properties let on short lease terms where the property is multi-let, and on schemes including several assets let on flexible lease terms, due to the portfolio effect. However, this is not easily modelled in a lease pricing system. It therefore represents an advantage for larger owners able to exploit the risk reduction explained by standard portfolio theory.

The price impact of flexible leases will also be affected by the portfolio effect: a department store or anchor store has much greater impact on a shopping centre than other tenants, so the rent impact of a break is much bigger.

\section{Lessor options}

Flexible lease pricing provides the parties with more options both in the standard sense and in the financial sense. Lessee options are most obviously introduced by tenants' break clauses. They have a value to the tenant based on the occupation alternatives they provide: remain, move, close down. They have a cost to the lessor based on the potential interruption to cash flow and the associated cost of running and re-letting an empty property. While it is difficult to estimate their value to a tenant using pure financial variables they can be valued by reference to the landlord's costs.

Interviewees found it relatively easy to find examples of break clauses and to comment on the likely rent impact. Typical were expectations such a 15\% premium for a 5 year break; a $7.5 \%$ premium for 10 year break; and $15 \%$ plus for both.

Tenants' break options may be countered by lessor options to break, which may cancel any price impacts. Less obviously, the grant of a lease outside the Landlord and Tenant Act 1954 removes a tenant option to stay and grants a lessor option to remove the tenant.

The value of these lessor options is less easy to model than the lessees' options. The financial cost of exercising a lessor break can be modelled using financial variables - namely the cost of running and re-letting an empty property - while the benefits of the option (which may include re-development options, or the opportunity to re-locate other tenants to free up space that be re-let at a higher rent and many others) are less easily priced. 


\section{Developing a model for the pricing flexible leases}

\section{$\underline{4.1 \quad \text { Introduction }}$}

It is apparent that there is a wide variety of factors affecting the financial implications of short leases and break clauses. Valuers are faced with the task of reflecting the rental and capital value implications of this diversity within their appraisals. It is well documented that when faced relatively novel lease structures, valuers tend to adopt conservative practices. Indeed there are rational grounds for such an approach. Consistent with other appraisal approaches to 'anomalies', the initial research on this topic found that valuers tend to use rather ad hoc adjustments to reflect the effects of break clauses (Lizieri and Herd,1994).

Although it may be argued that any application of generalised risk adjustments by market participants to account for break options should also be used by valuers in assessing market values, previous research has shown that established rules-of-thumb in valuation practice are often at odds with activities in the market or that there is diversity of application within the market (O'Roarty et al, 1997). Further, given the combination of asset heterogeneity, confidentiality and 'thin' trading, the usefulness of direct comparison methods of valuation will be limited. For break clauses, this drawback will be further exacerbated by the diversity of break clauses.

\section{$\underline{4.2 \quad \text { Simulation approaches }}$}

In this method of analysis, the distribution of possible outcomes is generated by a computer using randomisation based on specified probability distributions. Lizieri and Herd (1994) used simulation as a method of pricing break clauses. They examined approaches to the problem by practitioners and found a notable lack of consistency between valuers and in the internal logic of their assumptions.

They developed a simulation approach to formally account for the probability that tenants may exercise the right to prematurely determine the lease and found evidence of inconsistency in the application of yield adjustments as a remedy for the impact on value of break options. Indeed they concluded that in general valuers tended to adopt a conservative approach (presenting an opportunity for arbitrage trading). Their model derived the probability of tenant vacation from evidence about an 'average' rate of non-renewal by tenants.

However, given the diversity in the structure of break clauses and the heterogeneity of tenant circumstances, the applying 'average' probabilities is just as likely to fail to account accurately for the implications of break clauses and its application also to produce arbitrage possibilities. There is information available that can enable an estimation of the probability of tenant vacation.

\subsection{Analytical approaches - using option pricing theory}

Although simulation can be used to price financial options, specific mathematical equations have been proposed which generate similar outputs. There has been considerable interest in the potential application of option pricing techniques to property investment and development decisions (see Grenadier, 1995; Ward et al 1998; Patel and Sing, 1998 and Rowland, 1999). If the option to vacate is viewed from a typical option perspective the limitations of such methodologies can be seen.

In a typical option product the investor acquires the right to buy (call option) or sell (put option) an underlying asset before or at a pre-agreed date. In this case, since the problem is 
concerned with options to vacate, the similarity is with a European put option where the tenant has the right to vacate (sell) at a pre-agreed date. The value of the option is a function of movement in the price of the underlying asset. Logically, the price volatility of the underlying asset is a key determinant of the value of the option with increasing volatility producing higher option values. Although mathematically complex in derivation, the operation of option pricing models is relatively simple. The key variable - volatility - is either estimated from analysis of historic price data or is obtained by analysing implied volatility in transactions.

It can be recognised how the volatility of property rental and yield series can impact of the financial implications of an option to vacate. Where the rental value at the point of potential letting termination is lower than the rent passing, the right to vacate may act as a downward rent review. This point is further analysed below. However, reliable application of these pricing models is, therefore, predicated on reliable historic time series and/or adequate transaction data. There are well documented problems with both these requirements in the commercial property market. Moreover, even in markets which are relatively deep, misestimation of volatility is a problem in valuing options (Hodges, 1990).

A good example of the limitations of the application of option pricing models to break clauses is Ward (1997). He presents an approach derived from the binomial option pricing model. Ward identifies volatility in rents as the primary factor affecting value making assumptions about the circumstances in which the tenant will vacate. Pricing outcomes are presented on the basis of a range of assumptions about rental volatility. Moreover, the focus on future rental levels (and associated volatility) ignores the role of other issues such as tenant circumstances and break clause structure. The emphasis on volatility as the primary determinant of option value will be more appropriate where there is uniformity in the structure of the option but may be problematic where there is heterogeneity in the probability of exercise. In a typical European option, the rational investor will always exercise the option when they are 'in the money'. However, in the property market we have seen that each break option is unique in terms of structure of the option and the tenant attitude to exercise.

It is illuminating to contrast this study with the case of pricing upward/downward rent reviews (Ward and French, 1997). In his case, the rationale for the application of option pricing models seems more appropriate. Where the open market rental value is below the rent passing, the rent will always fall in the case of a non-upwardly only rent review: the option will be exercised since it is 'in the money'. Ward's break option pricing model assumes that this rule also hold for break clauses. In reality, tenants may choose to exercise the break whether rents have fallen or not and in some cases may be unwilling to use the 'threat' of break to lower the rent. Moreover, in the case of downward rent reviews also, the pricing implications are dependent upon the volatility assumption and Ward and French (1997) demonstrate the relatively wide range of possible volatility-dependent pricing outcomes (see 4.5 below).

It is clear that both option pricing and simulation approaches can provide similar solutions to lease pricing issues. However, simulation seems more suitable in this context for a number of reasons.

- It can be carried out using spreadsheet-compatible analytical systems such as Crystal Ball or @RISK.

- The outputs can be integrated into conventional spreadsheet models.

- It is flexible enough to cope with non-standard or unusual situations/assumptions.

- It is relatively transparent and permits the analyst to identify the key determinants of the outputs. 


\subsection{Case study: OPRent}

OPRent is a simulation based system which is now being adopted in the UK property market. It uses the above research and theory to change the way in which property owners think about income streams, moving from a deterministic approach to a probabilistic approach. Two illustrative examples are used here.

Simulation 1: Moving from a 15 year lease with 5-yearly upward-only rent reviews to a 10 year lease with a 5 year break

\section{Assumptions}

Rental value on a standard lease: $£ 100,000$ with one year rent free

Lease renewal probability: $20 \%$

Lease break probability: $25 \%$

Expected void: 3 quarters

Void volatility: 3 quarters

Empty property costs: $£ 10,000$ a year

Re-letting costs: $£ 25,000$

Expected rental growth: $1 \%$

Rental growth volatility: $4 \%$

Target return: 9\%

\section{Result}

The required year 1 rent increases by $36 \%$ (see Table 2).

Table 2: Simulation 1 outputs (shorter lease with break)

\begin{tabular}{|lll|}
\hline Year & Cash flow: standard $(£)$ & Cash flow: flexible $(£)$ \\
1 & 0 & 0 \\
2 & 100000 & 135900 \\
3 & 100000 & 135900 \\
4 & 100000 & 135900 \\
5 & 100000 & 135900 \\
6 & 108100 & 82492 \\
7 & 108100 & 87969 \\
8 & 108100 & 104576 \\
9 & 108100 & 107424 \\
10 & 108100 & 107484 \\
11 & 115908 & 25200 \\
12 & 115908 & 53931 \\
13 & 115908 & 104907 \\
14 & 115908 & 113256 \\
15 & 115908 & 113256 \\
\hline
\end{tabular}

\section{Explanation}

The higher cash flow for the flexible lease acts as compensation for the owner, but can be lost at the first review where a break operates. At this point there is a $25 \%$ chance of a break being exercised, and the system assumes a $100 \%$ chance of any tenant using the break to bring the rent back down to the market level. 
After the break, there is a chance of a void and associated costs. The probability of a void falls, and the cash flow improves with every passing quarter.

At the lease end in year 10, the chance of a lease renewal is very small and the cash flow recovers only as the probability of a re-letting after an expected void period rises with passing time.

Simulation 2: Moving from a 15 year lease with 5-yearly upward-only rent reviews to a 15 year lease with rent reviews which operate in either direction

\section{Assumptions}

Rental value on a standard lease: $£ 100,000$ with one year rent free

Lease renewal probability: $20 \%$

Lease break probability: $25 \%$

Expected void: 3 quarters

Void volatility: 3 quarters

Empty property costs: $£ 10,000$ a year

Re-letting costs: $£ 25,000$

Expected rental growth: $1 \%$

Rental growth volatility: $8 \%$

Target return: 9\%

Result

The required year 1 rent increases by $6 \%$ (see Table 3).

Table 3: Simulation 2 outputs (moving from upward only reviews)

\begin{tabular}{|lll|}
\hline Year & Cash flow: standard $(£)$ & Cash flow: flexible $(£)$ \\
1 & 0 & 0 \\
2 & 100000 & 105712 \\
3 & 100000 & 105712 \\
4 & 100000 & 105712 \\
5 & 100000 & 105712 \\
6 & 114288 & 112322 \\
7 & 114288 & 112322 \\
8 & 114288 & 112322 \\
9 & 114288 & 112322 \\
10 & 114288 & 112322 \\
11 & 126996 & 119580 \\
12 & 126996 & 119580 \\
13 & 126996 & 119580 \\
14 & 126996 & 119580 \\
15 & 126996 & 119580 \\
\hline
\end{tabular}

\section{Explanation}

The key here is to compare the expected rental value using $1 \%$ rental growth $(£ 112,322$ at year 6 and $£ 119,580$ at year 11) with the expected cash flows under these two leasing options. The two-way rent review picks up exactly these values, which represent the mean cash flow where rental growth can be higher or lower than expected. The upward-only rent review picks up a higher value, which is defined as the mean cash flow where rental value 
growth has an expected value and a positively skewed distribution, with zero being the lowest possible value.

In many ways, the more interesting questions raised by this paper are to do with the possibility that the result of this technology will be accepted by market participants with a traditional view of property income. This impacts on lease pricing but also has implication for capital values and valuation/pricing/appraisal.

\section{$\underline{4.5 \quad \text { Valuation }}$}

The implications for pricing are best illustrated by using an example.

Assume the rental value of a property let on a standard lease is $£ 100,000$. The market capitalisation rate that would be applied is $7 \%$, and a valuation of $£ 1,428,000$ would result.

In DCF terms, a required return or target IRR of $9 \%$ might be decided as appropriate. If the price of $£ 1,428,000$ is 'correct' the implied perpetuity rental growth rate required to deliver the return is $2.29 \%$. A DCF analysis using these inputs would confirm a present value of the expected income stream of $£ 1,428,000$.

Now rental growth volatility of $8 \%$ is added to the problem. The value of the standard lease is impacted by this variable, as it includes upward-only rent reviews which create a prism through which effective cash flow growth is magnified. The greater the volatility, the greater the value of the lease with the upward only review. The following question arises: does the market value of $£ 1,428,000$ reflect the impact of rental growth volatility? If so, how can that market price be de-constructed and explained?

A required return of $9 \%$ and expected market rental growth of $2.28 \%$ produces a value of $£ 1,428,000$ only if rental growth volatility takes a value of zero.

If we accept that the price is the result of efficient market pricing, and that the market understands the impact of rental growth volatility, one of the inputs must change. This has to be either the IRR, which will be lower in a world which recognises volatility (8\%), or alternatively volatility-adjusted rental growth must be lower (1.49\%).

If we do not accept that price is the result of efficient market pricing, and that the market may not understand the impact of rental growth volatility, then we may assume that the $9 \%$ IRR and the implied rental growth values are fixed. The valuation then rises to $£ 1,575,000$ to take account of volatility.

Which is the more likely explanation of this dilemma? This is a matter for further exploration. OPRent is now being extended into valuation and investment appraisal applications, and the making explicit of the implicit relationships will be explored in further work. 


\section{References}

Baum, A (2003): OPRent Research Report 2003, Reading, OPS.

Baum, A., Crosby, N. and McAllister, P. (2001) Pricing Lease Terms in the Retail Sector, University of Reading: Department of Land Management Working Paper.

Corporate Intelligence Group, (1993) Market Research Survey, reported in DoE Consultation Paper on Commercial Property Leases: Response by IPF, London, Investment Property Forum.

Crosby, N., Murdoch, S. and Markwell, S. (2000) Monitoring the Code of Practice for Commercial Leases, London: Department of the Environment, Transport and the Regions, 2000,152pp + App 236pp.

Crosby, N. and Murdoch, S. (1997) The influence of procedure on rent determination in the commercial property market of England and Wales, Paper delivered at RICS 'Cutting Edge' Research Conferences, Dublin, 1997.

Crosby, N., Lizieri, C and Murdoch, S. (1998) Changing Lease Structures in Real Estate Office Markets, Paper delivered at ERES/AREUEA conference, Maastricht.

Drivers Jonas (1997) Commercial Leases - A Permanent Revolution, Drivers Jonas Research.

Grenadier, S. (1995) Valuing lease contracts: A real-options approach, Journal of Financial Economics, Vol .38, pp. 297-331.

Hodges S D (Ed) (1990), Options: Recent Advances in Theory and Practice, Manchester University Press, 1990.

Lizieri, C. and Herd, G. (1994) Valuing and appraising new lease forms: the case of break clauses in office markets, Proceedings of RICS The Cutting Edge property research conference, September, 1994.

Lizieri, C. (for the Business Space Research Team) (1997) The changing market for business space: occupier requirements, market response and valuation impacts, Paper delivered at RICS 'Cutting Edge' Research Conference, Dublin, 1997.

McAllister, P (2000). Pricing Short Leases And Break Clauses Using Simulation Methodology, University of Reading: Department of Land Management Working Paper.

McAllister, P. and O'Roarty, B. (1998): The legal and valuation implications of break clauses: a behavourial perspective, Paper delivered at RICS Cutting Edge conference, de Montfort University, 1998.

McAllister P. and O'Roarty, B. (1999): Pricing break clauses: a fundamental approach, Paper delivered at the RICS Cutting Edge conference, Cambridge.

O'Roarty, B., McGreal, S. and Adair, A. (1997): The impact of retailers store selection criteria on the estimation of retail rents, Journal of Property Valuation and Investment 15 (2) pp 119130. 
Patel, K. and Sing, T.F. (1998): Application of Contingent Claim Valuation (Real Option) Model for Property Investment Analysis, Paper delivered at RICS 'Cutting Edge' Conference, de Montfort University, 1998.

Reynolds, K. (1997): Can Tenants Use Break Clauses to Re-negotiate Rents Downwards?, in Proceedings of Henry Stewart Conference Studies, Break Clauses, London.

Rowland, P. (1999): Pricing lease covenants: turning theory into practice, Paper delivered at PRRES conference, Kuala Lumpur.

Slessenger, E. and Ballaster, R. (1994): Tenants'break clauses, Estates Gazette, Issue 9446, pp.196-7.

Ward, C. (1997): Risk neutrality and the pricing of specific financial aspects of UK leases, Paper delivered at RICS 'Cutting Edge' Research Conferences, Dublin, 1997.

Ward, C., Hendershott, P. and French, N, (1998): Pricing Upwards Only Rent Review Clauses: An International Perspective, Journal of Property Valuation \& Investment, 16(5), 1998, 447-454.

Ward, C. and French, N. (1997): The Valuation of Upwards Only Rent Reviews: an Option Pricing model, Journal of Property Valuation \& Investment 15(2), 171-182.

www.OPRent.com 